\title{
EFFECTIVE PRACTICES OF COACHING DISABILITY SPORT
}

\author{
Jeffrey John Martin* \\ Wayne State University \\ Laurel Whalen \\ Wayne State University
}

*Corresponding author: Jeffrey John Martin:Wayne State University, Division of KHS, FAB Building,
Detroit, MI, USA, 48202 • Tel:313-577-1381 • Fax: 313-577-5999 • Email: aa3975@ wayne.edu

One of the most critical factors of sport performance is coaching. In this review paper we examine the pertinent literature on the historical trends in disability sport to provide discussion on the following: a) the negative ramifications (e.g., over-training, failing to taper) athletes often experience when they perform without a coach, b) the perceived challenges (e.g., not understanding an athlete's disability) of disability sport coaching of high-level coaches, c) the positive outcomes athletes experience (e.g., increased motivation and autonomy) when they have good quality coaching, and d) the necessary competencies (e.g., understanding the psychology of coaching) to be an effective disability sport coach. We also provide theory based suggestions for future research.

Key Words: Psychology, Paralympics, Adapted Sport, Education

\section{INTRODUCTION}

As many readers will know, optimal athletic development and sport success are almost always the product of multiple factors and maybe even more so for athletes with disabilities (Martin, 1999). One of the most critical factors is coaching. Historically, research on coaching athletes with disabilities, beyond descriptive data indicating whether athletes had coaches, was non-existent. In 1985, the Committee on Sports for the Disabled, a standing committee of the U.S. Olympic Committee, recommended seven research areas for disability sports, among them was the "selection and training of coaches involving selection methods, effectiveness of training programs, and coaches' background..." (in Reid \&
Prupas, 1998). While important theoretical and applied coaching research has added to the literature in the last 5-10 years, a 2013 document review conducted by Lee and Porretta which compared the disability sport literature from 20012011 to Reid and Prupas' (1998) review of the literature from 1986-1996, actually found a decrease in the frequency and percentage of both data-driven and review articles in the "Selection and training of coaches" category. The purpose of this article is to review the trends in research on coaching athletes with disabilities to make a recommendation for effective practices in disability sport. It should be noted, however, that much of the coaching literature implicitly directed to athletes without disabilities can also apply to 
athletes with disabilities given the many similarities between them (Dieffenbach \& Statler, 2012).

In this review paper we examine the pertinent literature on the historical trends in disability sport to provide discussion on the following: a) the negative ramifications athletes often experience when they perform without a coach, b) the perceived challenges of disability sport coaching among high-level coaches, c) the positive outcomes athletes experience when they have good quality coaching, and d) the necessary competencies to be an effective disability sport coach.

\section{METHODS}

Consistent with previous review articles on disability sport literature from Reid and Prupas (1998) and Lee and Poretta (2013), EBSCO databases, including PsycINFO, PsychARTICLES, MEDLINE, and ERIC were searched; however, the ProQuest database was also utilized in the search to ensure completeness of the results. Additional electronic searches were conducted via the Human Kinetics journals website, including, Adapted Physical Activity Quarterly, Kinesiology Review, Journal of Sport and Exercise Psychology, International Sport Coaching Journal, Journal of Clinical Sport Psychology, The Sport Psychologist, and Journal of Physical Activity and Health. In addition, several other sport psychology and physical activity journals were searched electronically, including Journal of Applied Sport Psychology, Research Quarterly for Exercise and Sport, Psychology of Sport and

Exercise, Sport Psychology, and Journal of Sports Sciences.

Several other search strategies were used, as recommended by Lee and Poretta (2013), including citation-index searching, ancestry searching, and inspecting reference lists for applicable citations. The relevant electronic databases were examined using key words (and combinations therein), including "disability sport," "coaching," "sport psychology," "Paralympics," and "disabled athletes" (terminology used by ProQuest). Search words were identified through analysis of journal abstracts and the key words included in various articles. For the purposes of this review, articles published in peer-reviewed journals were primarily used and years of publication were restricted to 1985-2015.

\section{Historical trends in coaching disability sport}

Until recently, many disability sport athletes have had to coach themselves. For example, in a study done over 25 years ago, Rainbolt and Sherrill (1987) reported on 100 of 207 athletes competing in the United States Association for Blind Athletes games. They found that $22 \%$ of the athletes did not have a coach and that of those who had a coach, $43 \%$ of the athletes usually did not have that coach present during practices. In a study of elite wheelchair roadracers, Hedrick and colleagues found that only a minority (e.g., 2) of 17 males had a coach (Hedrick, Morse, \& Figoni, 1988). Ferrara and Buckley (1996) indicated that only $58 \%$ of 319 American elite adult athletes had coaches during their training for the 1992 Paralympic Games. Fortunately, in recent years athletes from wealthy countries have been increasingly supported by high quality coaching. Canadian Paralympic swimmers, for instance, have access to the same high-level coaches as nondisabled swimmers. Conversely, Paralympians from countries without the financial resources of European or North American countries are much more likely to be deprived of professional coaching support (Crawford \& Stodolska, 2008; Wilson \& Khoo, 2013). While some athletes may 
prefer not to have coaches, many athletes are still self-coached out of necessity. Other athletes receive sub-optimal coaching given that many coaches may not have the appropriate sport science or adapted physical activity education or experience.

Furthermore, the need for increased coaching quality has been recognized by national organizations. For instance, the American Association of Adapted Sports Programs offers an eight-hour coaching certification course that covers diverse topics such as sport psychology, physiology, management and philosophy. Coaching education researchers are also starting to take note of athletes with disabilities and best coaching practices (Vargas, Flores, \& Beyer, 2012). Most coaches only have prior experiences with able-bodied athletes, which heightens the importance of finding sport-specific coaching literature in the disability sport context. A common complaint among disability-sport coaches has been the challenge in finding quality coaching references; however, a recent increase in research and disability sport literature (e.g., Goosey-Tolfrey, 2010). has made finding relevant coaching material easier.

It should be noted that not all disability sport coaching education opportunities are embraced. A prominent UK disability sport coach, Robert Ellchuk, has stated that weekend coaching clinics were, ". $\ldots$ the biggest waste of time that I have ever experienced in my entire life" (Bush \& Silk, 2012, p. 473). Disability sport coaches in Canada have also noted that lower level coaching classes (e.g., Level 1, National Coaching Certification Programme (NCCP) may be too elementary (McMaster et al., 2012). Hence, top down administrative directives requiring coach attendance can be counter-productive if coaches view the information and material delivered as below their current level of expertise.

\section{Negative athlete outcomes}

As a result of the lack of formal coaching, it is understandable that many disability sport athletes have been known to train poorly. This can consist of over-training, training inconsistently, in nonsport-specific ways, failing to taper for major competitions, and failing to rest after major competitions. In one older study of national-level wheelchair athletes, the researchers found that they failed to adequately set goals and plan their training and competition schedules (Watanabe, Cooper, Vosse, Baldini, \& Robertson, 1992). Athletes without coaches have also been found to engage in poor nutritional practices, such as ingesting excessive protein supplements (Hedrick et al., 1988).

Wheelchair road racing athletes often develop upper respiratory illnesses after marathons, and inadequate post-race recovery often exacerbates their difficulties. For athletes who self-coach, finding sport-specific information that is both accurate and appropriate is often a challenge. The lack of disability specific coaching materials has been an ongoing issue for over 25 years (Depauw, 1986; McMaster, Culver, \& Werthner, 2012).

\section{Coaching attitudes}

Given that, in general, people with disabilities often face discrimination and prejudice, researchers have examined whether coaches, in general, are receptive to working with them (Flores, Beyer, \& Vargas, 2012; Kozub \& Porretta, 1998). A survey of almost 400 American coaches indicated that, overall, they were supportive of school-based sporting opportunities for adolescents with disabilities. However, the same coaches did not feel that their training was adequate to coach them. Flores et al. (2012) examined the attitudes of 36 coaches towards 
athletes with hidden disabilities. Similar to Kozub and Porretta (1998) coaches were very supportive of including athletes with disabilities in interscholastic sport, but did not feel sufficiently prepared to coach them. These findings were consistent with a study of almost 500 coaches in Hungary, whereby almost three-quarters of them believed that coaching education curriculums should contain information on coaching athletes with disabilities, and most had no experience coaching athletes with disabilities (Dorogi, Bognár, \& Petrovics, 2008). Novice coaches of parasailing athletes in Canada expressed similar sentiments (Davey, 2014), as they were uncertain of parasailing specifics (e.g. helping athletes transfer into the boat) and were concerned for the athlete's physical safety. Coaches were also cognizant of not wanting to offend their athletes by using inappropriate language (Davey, 2014). The coaches in this study reported learning these disability-sport specific skills on the job, and, in general, expressed positive cognitions and feelings about their experiences.

\section{Coaching challenges}

One of the rationales for conducting research on coaches of athletes with disabilities is that, despite many similarities, there might still be some important differences between the effective practices in disability sport and able-bodied sport. Disability sport coaches believe they have the dual challenge of understanding their athlete's sport and their disability. This was evidenced in a recent study of the roles and responsibilities of four elite wheelchair rugby coaches of wheelchair rugby players, in which two themes emerged: coaching the sport and coaching the individual (Tawse, Bloom, Sabiston, \& Reid, 2012). In regards to "coaching the sport," coaches perceived that elite disability sport was in a period of transition and emphasized the importance of creating an elite sporting environment. Coaches believed that the most experienced athletes struggled with the increased expectations relative to the past when making a national team was not as difficult. In the "coaching the individual" theme, coaches emphasized the importance of changing the mindset of athletes to accepting the need for regular workouts beyond team practices (Tawse et al., 2012).

Similar to the coaches interviewed by Tawse et al. (2012) elite swimming coaches also affirmed the value of coaching swimmers as "elite swimmers" versus coaching a "swimmer with a disability" (Cregan, Bloom, \& Reid, 2007). However, it should be noted that Robbins and colleagues interviewed basketball $(N=14)$ coaches of both wheelchair and stand up basketball athletes and found very few differences between them in terms of coaching philosophy, expectations, and perspectives on their athletes (Robbins, Houston, \& Dummer, 2010). Furthermore, any differences between the groups were not any greater than the differences within each group (Robbins et al., 2010). At the same time, the Canadian based "Sport for Life" program has slightly difference stages of long-term athlete development (LTAD) for individuals with disabilities compared to able-bodied athletes. For instance, an "awareness" and "first contact" stage have been added for disability sport. (Canadian Sport for Life (CSL), 2012). The awareness stage is designed to heighten the need to inform individuals with disabilities and the general public of sport and physical activity (PA) opportunities for individuals with disabilities. The first contact stage is designed to alert sport organizations and coaches of the need to provide positive and encouraging initial experiences to individuals with disabilities. The CSL perspective suggests that the limited disability sport opportunities and knowledge of those opportunities are restricting factors to sport entry. Additionally, once in sport 
the CSL perspective suggests that the retention of athletes with disabilities is particularly critical. As we explain next there are some differences between disability sport and able-bodied sport that coaches should be cognizant of as such differences have implications for coaching practices.

Quality coaching provided by knowledgeable coaches is clearly an important influence on athletic success. In addition to the knowledge a coach possesses the coach-athlete interpersonal relationship is also critical (Davey, 2014; Jowett, 2003). For instance, in a study of eight swimmers with disabilities, a major finding was that all the athletes indicated that the positive outcomes they experienced in sport were linked to a very personal and close relationship with the coach (Turnnidge, Vierimaa, Côté, 2012).

\section{Positive athlete outcomes}

Satisfaction, motivation and cohesion. Although the research on disability sport and coaching is limited, there is a sufficient amount to lend support to the value of good coaching in disability sport. Disability sport athletes who view their coaches as supporting their autonomy expressed a strong sense of control over their sport involvement and had positive relationships with their teammates (Banack, Sabiston, \& Bloom, 2011). Also, athletes who viewed their coaches as supporting their desire to be independent had higher levels of intrinsic motivation relative to athletes who perceived their coaches as less supportive. Banack et al's (2011) research on Canadian athletes has been supported by similar research with Jordanian national level athletes with disabilities (Hatamleh, Al-Ruz, \& Hindawi, 2009). In general the athletes viewed their coaches as endorsing ( $M$ 's $=3.05$ to 4.01 ) various effective leadership behaviors (e.g., training and instruction, social support, positive feedback) from "occasionally" to "often." (Hatamleh et al. 2009).
In this study, athlete satisfaction with coaches was also determined, and athletes were moderately ( $M$ $\approx 5$ on a 7 point scale) satisfied with coaches' training and instruction, and the personal treatment they received from them.

Finally, the authors also examined if athletes who had more favorable perceptions of coaching leadership behaviors were also more satisfied with their sport experience. Athletes were more satisfied with their training, personal treatment, and team and individual performances when they perceived coaches as providing more social support, positive feedback, democratic behavior, and training and instruction compared to athletes who were less satisfied. Additionally, autocratic leadership was only minimally related with athlete satisfaction; athletes were less satisfied with how they were treated (i.e., personal treatment) if they viewed their coaches as employing more autocratic leadership behaviors. Autocratic behavior was unrelated to athlete satisfaction with training and instruction and team and individual performance.

Cumulatively, these findings reported by Hatamleh et al. (2009) suggest that democratic behavior is positively linked to various forms of satisfaction, but autocratic behavior is only linked to one form of satisfaction. The strongest correlations tended to be linked to athlete training and instruction satisfaction or coach's leadership behavior in training and instruction. The later finding highlights the value of coaches focusing on providing high-level instruction (e.g., communicates expectations, corrects mistakes, provides instruction, etc.). Coach influence on team cohesion is particularly important for sports where strategic and set plays are common (e.g., wheelchair rugby and basketball), and need to be learned in a short time span. Complicating this, National team athletes often live in different parts of the country, making the development of team cohesion difficult. Hence, coach influence on team 
task and social cohesion at National team camps is critical.

Confidence, anxiety and performance. Disability sport coaches also influence critical competitive psychological states in their athletes; in particular, confidence and anxiety, which play an important role in athlete's sport performances. For example, coaches who simultaneously support and challenge their athletes to become better are more likely to develop confident athletes (Martin \& Mushett, 1996). Athletes in a study by Campbell and Jones (2002) viewed negative coaching behavior as one of the most anxiety inducing sport stressors they encountered. Effective coaching can clearly aid athlete's performances as demonstrated by Burkett and Mellifont (2008). Using effective sport science techniques, such as video and race analysis data, coaches were able to aid Australian athletes in developing effective race strategies (e.g., even pacing) that ultimately lead to an initial $10 \%$ performance improvement, followed by a smaller improvement that ultimately resulted in a world record. In a single-case study, de Bressey de Guast and colleagues (2013) also reported that the use of a psychological skills training program was effective in advancing the sporting performances and mental skills of an elite wheelchair waterskiing athlete (de Bressey de Guast, Golby, Van Wersch, \& Arripe-Longueville, 2013).

\section{Effective disability sport coaching}

"If you are coaching a swimmer with a disability it's important to have good knowledge of what the disability is, that way you can make the distinction between what they can't do because of the disability or because they chose not to. It can be a fine line figuring out how far you can push the athlete, but you have to understand the disability so you can make the right decisions (Cregan et al, 2008, p. 346)”
As the above quote indicates, coaches must gain knowledge of their athlete's disability condition. Because most coaches lack the life experience of living with a disability, disability specific knowledge must be learned. This would suggest that experiences in the disability sport one aspires to coach would be of value. Older sledge hockey athletes have stated that they thought their coaches would be more effective if they knew how to play sledge hockey. In fact one athlete thought his coach's lack of sledge hockey experience was “almost counterproductive and it doesn't really teach us anything" (Wynnyk \& Spencer-Cavaliere, 2013, p. 306). However, two coaches with disabilities (wheelchair basketball and wheelchair rugby), who coached athletes with disabilities, did not believe that it was critical to have had athletic experiences as an athlete with a disability (McMaster, Culver, \& Werthner, 2012). At the same time, McMaster and colleagues and Davey (2014) found that coaches overwhelming viewed informal experiences (e.g., hands-on clinics, mentoring relationships, talking to athletes) as important components of a coaching education. For coaches of youth athletes, developing sound relationships with an athlete's parents and their physical therapists can help capture their unique needs. Additionally, maintaining a positive relationship with athletes is also quite important (Davey, 2014; Fitzgerald, 2013; McMaster et al. 2012).

Disability sport coaches are also positioned to support the development of mental skills in their athletes. Although researchers in able-bodied sport have examined coaches' views of psychological skills and the value of sport psychologists, only one group of researchers have targeted similar questions in disability sport. In a interview study of ten Portuguese elite disability sport coaches, Bastos and colleagues established two important themes related to sport psychology (Bastos, Corredeira, Probst, \& Fonseca, 2014). 
First, all of the coaches believed that psychological preparation was important and psychological skills were invaluable in helping athletes with disabilities be psychologically prepared. Second, while all the coaches believed that sport psychologists were important (and were receptive to working with one), only one coach was working with a sport psychologist at the time of the study. Finally, coaches believed that a lack of time, funding, and athlete willingness were barriers to having sport psychologists involved in elite level disability sport.

In addition to understanding the challenges specific to working with athletes with disabilities, coaches in disability sport must also consider the challenges that their athletes face when interacting with their environment. Unlike coaches of able-bodied athletes, disability sport coaches must also consider the competition facility's accessibility for their athletes. For example, sometimes practice facilities have doors too narrow for wheelchairs (McMaster et al. 2012) or inaccessible locker rooms and shower facilities. Disability sport coaches must also consider the barriers their athletes may face when traveling. Unlike an able-bodied basketball team, for example, a wheelchair basketball team cannot simply rent a bus to get to a tournament. They must make arrangements for the transport of chairs and secure handicap-accessible vehicles. This often requires the individual athletes or their families to transport themselves. Additionally, coaches of high performance sport athletes (e.g., Paralympians) must support their athletes with issues related to traveling to National and International competitions. For example, it is customary for individuals with disabilities to board a plane first and be among the last off. For elite-level athletes, this can result in stress and pressure sores from extended sitting. Wheelchairs are typically stored during flight, which makes any mobility, including accessing restrooms, difficult without assistance. Additionally, flying can promote dehydration, which is of particular concern for elite athletes, and necessitates the regular access to water.

Ethical issues garner attention in all areas of sport, and are certainly not unique to disability sport, but coaches in this discipline face unique concerns. Bredahl (2011) outlines a number of potential ethical issues related to disability sport and the Paralympics, in particular. Unique to disability sport is the classification process whereby athletes are equated across functional ability, so they do not have to compete against athletes with less severe impairments. This system is often equated with weight classifications in wrestling or boxing, but has come under scrutiny by a number of authors (e.g., Howe \& Jones, 2006; Mills \& Krassioukov, 2011). Bredahl (2011) suggests that coaches need to be cognizant of athletes who may cheat (known as sandbagging) to get classified at a level lower than their capabilities, resulting in facing inferior competition and increased odds of winning. Certainly, disability sport coaches should be cognizant of this practice and insure their athletes do not engage in it. The use of performance enhancing drugs is also present in disability sport and is unethical and unsafe. Bredahl (2011) argues for increased coaching education that focuses on ethical issues and, in particular, the disability classification system.

Finally, it is important that coaches in disability sport understand their influence even after they are no longer coaching. For instance, upon retirement one athlete remarked:

"Nobody phoned, nobody asked me whether I would like to swim a little bit... so I didn't swim, maybe gained some weight...nobody fought for me, including coaches and friends, I felt so small..(Hutzler \& Bergman, 2011, p. 8). 
This quote suggests that coaches should consider whether they have a responsibility to help athletes transition out of sport by continuing to provide emotional support after they stop competitions (Martin, 2011; Martin \& Wheeler, 2011).

\section{SUMMARY AND FUTURE RESEARCH DIRECTIONS}

Historically, athletes with disabilities have lacked coaching. Although athletes from countries like Canada, the USA and the UK are starting to benefit from quality coaching, it is important to recognize that many athletes from around the world have very limited or no coaching at all (Wilson \& Khoo, 2013). In addition to the challenges of coaching in general, adapted sport coaches often face additional issues that are quite unique to disability sport, including understanding the nuances of their athletes' disabilities, dealing with accessibility issues, and navigating travel logistics. The limited research on disability sport coaching practices also suggests that coaches can be quite influential on their athlete's psychological states (e.g., satisfaction, motivation, confidence, etc.).

Future researchers are encouraged to continue theory-based research in an effort to understand the determinants of effective disability sport coaching practices. Of course, understanding how coaches, in turn, influence their athlete's long-term development and immediate performances are also of value. There are several models that have been used to measure effectiveness in able-bodied athletes that are worth mentioning for replication with athletes with disabilities. Horn's (2008) coaching model is an excellent theory-based model that has been effectively used to examine coaching effectiveness in able-bodied sport. This study also provides examples of qualitative research based in grounded theory which has the potential for revealing unique considerations in disability sport that might be over-looked by only examining a limited number of theory derived constructs. Future researchers will also benefit from Horn's (2008) comprehensive review of both coaching behavior questionnaires $(N=9)$ and observational systems $(N=4)$ for documenting coaching behaviors. While both questionnaires and observational systems might have to be adapted for disability sport contexts, such research tools provide a starting point for researchers new to coaching, psychology, and disability sport. Additionally, the value of the coach-athlete relationship seems to underscore the need for additional research on coaching practices that promote strong relationships. Given the limited theory-based research in disability sport coaching, the number of important questions that need to be addressed with quality research is almost limitless.

\section{REFERENCES}

Banack, H. R., Sabiston, C. M., \& Bloom, G. A. (2011). Coach autonomy support, basic need satisfaction, and intrinsic motivation of Paralympic athletes. Research Quarterly for Exercise and Sport, 82, 722-730. DOI: 10.1080/02701367.2011.10599809

Bastos, T., Corredeira, R., Probst, M., \& Fonseca, A. M. (2014). Elite disability sport coaches' views on sport psychology. International Journal of Psychological Studies, 6, 33-44. DOI: 10.5539/ijps.v6n1p33

Bredahl, A. M. (2011). Coaching ethics and Paralympic sports. In A.R. Hardman and C. Jones (Eds.), The ethics of sport coaching (1st ed.) (pp. 135-146). New York: Routledge.

Burkett, B., \& Mellifont, R. (2008). Sport science and coaching in Paralympic swimming. International Journal of Sports Science and 
Coaching, $3, \quad$ 105-112. DOI: 10.1260/174795408784089324

Bush, A. J., \& Silk, M. L. (2012). Politics, power $\&$ the podium: coaching for Paralympic performance. Reflective Practice, 13(3), 471-482.

Campbell, E. \& Jones, G. (2002b). Cognitive appraisal of sources of stress experienced

by elite mate wheelchair basketball players. Adapted Physical Activity Quarterly, 19, 100108.

Canadian Sport for Life (2012). Canada. Retrieved February 4, 2012 from http://www.canadiansportforlife.ca/athletesdisabilities/ltad-stages

Crawford, J. L., \& Stodolska, M. (2008). Constraints experienced by elite athletes with disabilities in Kenya, with implications for the development of a new hierarchical model of constraints at the societal level. Journal of Leisure Research, 40(1), 128-155.

Cregan, K., Bloom, G. A., \& Reid, G. (2007). Career evolution and knowledge of elite coaches of swimmers with a physical disability. Research Quarterly for Exercise and Sport, 78, 339-350. DOI: 10.1080/02701367.2007.10599431.

Davey, J. (2014). How do novice para sport coaches develop their knowledge? A look at experiences of para sailing coaches. Retrieved from:

http://www.ruor.uottawa.ca/handle/10393/306 47

de Bressy de Guast, V., Golby, J., Van Wersch, A., \& d'Arripe-Longueville, F. (2013).

Psychological skills training of an elite wheelchair water-skiing athlete: A single-case study. Adapted Physical Activity Quarterly, 30. 351372.

Depauw, K. (1986). Research on sport for athletes with disabilities. Adapted Physical Activity Quarterly, 3, 292-299.
Dorogi, L., Bognár, J., \& Petrovics, L. (2008). Introducing disability issues into the education of coaches. Physical Education and Sport, 52 $39-45$

Dieffenbach, K. D., \& Statler, T. A. (2012). More similar than different: The psychological environment of Paralympic sport. Journal of Sport Psychology in Action, 3, 109-118. DOI: 10.1080/21520704.2012.683322

Ferrara, M. S., \& Buckley, W. E. (1996). Athletes with disabilities injury registry. Adapted Physical Activity Quarterly, 13, 74-83.

Fitzgerald, H. (2013). The Coaching chain: Reflections of disabled athletes and coaches. A report for sports coach UK. Research institute for sport, physical activity and leisure. Leeds Metropolitan University.

Flores, M., Beyer, R., \& Vargas, T. (2012). Attitudes toward preparing youth sport coaches to work with athletes with hidden disabilities. Palaestra, 26, 5-6.

Goosey-Tolfrey, V. (Eds.). (2010). Wheelchair sports: A complete guide for athletes, coaches, and teachers. Champaign, IL: Human Kinetics.

Hatamleh, M. R., Al-Ruz, H. H. A., \& Hindawi, O. S. (2009). Coach's leadership behavior as a predictor of satisfaction with leadership: Perceptions of athletes with physical disabilities. International Journal of Applied Educational Studies, 4, 14-33.

Hedrick, B. N., Morse, M. I., \& Figoni, S. F. (1988). Training practices of elite wheelchair roadracers. Adapted Physical Activity Quarterly, 5, 140-153.

Horn, T.S. (2008). Coaching effectiveness in the sport domain. In T.S. Horn (Ed.), Advances in sport psychology (3rd ed.) (pp. 239-268). Champaign, IL: Human Kinetics.

Howe, P. D., \& Jones, C. (2006). Classification of disabled athletes: (dis)empowering the Paralympic practice community. Sociology of Sport Journal, 23, 29-46. 
Hutzler, Y., Bergman, B. (2011). Facilitators and barriers to participation while pursuing an athletic career: Retrospective accounts of swimmers with disabilities. Therapeutic Recreation Journal, 45, 1-16.

Jowett, S. (2003). When the honeymoon is over: A case study of a coach-athlete dyad in crisis. The Sport Psychologist, 17, 446-462.

Kozub, F. M., \& Porretta, D. L. (1998). Interscholastic coaches' attitudes toward integration of adolescents with disabilities. Adapted Physical Activity Quarterly, 15, 328344.

Lee, J. \& Porretta, D. (2013) Document analysis of sports literature for individuals with disabilities. Perceptual and Motor Skills, 116, 847-858.

Martin, J. J. (2011). Disability and sport psychology: In T. Morris, \& P. Terry. Sport and Exercise Psychology: The Cutting Edge. (pp. 609-623). Morgantown, WV: Fitness Information Technology, Pub.

Martin, J. J. (1999). A personal development model of sport psychology for athletes with disabilities. Journal of Applied Sport Psychology, 11, 181-193. DOI: 10.1080/10413209908404199

Martin, J. J. \& Mushett, C. A. (1996). Social support mechanisms among athletes with disabilities. Adapted Physical Activity Quarterly, 13, 74-83.

Martin, J. J. \& Wheeler, G. (2011). Sport Psychology. In Y. Vanlandewijck, \& W. Thompson. The Paralympic Athlete. (pp. 113136). London, England: International Olympic Committee.

McMaster, S., Culver, K., \& Werthner, P. (2012). Coaching of athletes with a physical disability: a look at their learning experiences. Qualitative Research in Sport, Exercise, and Health, 4, 226-243.

DOI:

$10.1080 / 2159676 X .2012 .686060$
Mills, P. B., \& Krassioukov, A. (2011). Autonomic function as a missing piece of the classification of Paralympic athletes with spinal cord injury. Spinal Cord, 49, 768-776. DOI: $10.1038 /$ sc.2011.2

Myers, N., Feltz, D., \& Chase, M. (2011). Proposed modifications to the conceptual model of coaching efficacy and additional validity evidence for the coaching efficacy scale II-high school teams. Research Quarterly for Exercise and Sport, 82, 79-88.

O’Rourke, D. J., Smith, R. E., Smoll, F. L., \& Cumming, S. P. (2014). Relations of parentand coach-initiated motivational climates to young athletes' self-esteem, performance anxiety, and autonomous motivation: Who is more influential?. Journal of Applied Sport Psychology, 26, 395-408.

Rainbolt, W. J., \& Sherrill, C. (1987). Characteristics of adult blind athletes, competition experience, and training practices. In M.E. Berridge \& G.R. Ward (Eds.), International Perspectives on Adapted Physical Activity, (pp. 165-171).

Reid, G., \& Prupas, A. (1998). A documentary analysis of research priorities in disability sport. Adapted physical activity quarterly, 15, 168-178.

Robbins, J.E., Houston, E. \& Dummer, G. M. (2011). Philosophies and expectations of wheelchair and stand-up collegiate basketball coaches. Journal of Sport Behavior, 33, 42-62.

Tawse, H., Bloom, G. A., Sabiston, C. M., \& Reid, G. (2012). The role of coaches of wheelchair rugby in the development of athletes with a spinal cord injury. Qualitative Research in Sport, Exercise and Health, 4, 206-225.

DOI: 10.1080/2159676X.2012.685104

Turnnidge, J., Vierimaa, M., Côté, J. (2012). An in-depth investigation of a model sport program for athletes with disabilities. 
Psychology, 3, 1131-1141. DOI: 10.4236/psych.2012.312A167

Vargas, T., Flores, M., \& Beyer, R. (2012). Coaching athletes with hidden disabilities: Recommendations and strategies for coaching education. Strategies, 25, 32-33.

Watanabe, K. T., Cooper, R. A., Vosse, A. J., Baldini, F. D., \& Robertson, R. N. (1992). Training practices of athletes who participated in the national wheelchair athletic association training camps. Adapted Physical Activity Quarterly, 9, 249-260.

Wilson, N. C., \& Khoo, S. (2013). Benefits and barriers to sports participation for athletes with disabilities: the case of Malaysia. Disability \& Society, 28, 1132-1145.

Wynnyk, K., \& Spencer-Cavaliere, N. (2013). Children's social relationships and motivation in sledge hockey. Adapted Physical Activity Quarterly, 30, 299-316. 